\title{
11: USE OF GUEST TECHNOLOGY TO PARAMETERISE A PHYSICALLY-BASED MODEL FOR ASSESSING SOIL ERODIBILITY AND EVALUATING CONSERVATION
}

\section{PRACTICES IN TROPICAL STEEPLANDS}

\author{
C.W.Rose, B.Yu, R.K.Misra, K.Coughlan and B.Fentie
}

Probably the largest body of data on soil erosion has been that collected using the USLE methodology, thus lacking measurement of runoff rates. In the ASIALAND section of this chapter it is demonstrated that the GUEST methodology can be applied to data collected for analysis using the USLE methodology. Thus there is the opportunity, in future, to analyse other USLE data sets to yield values of $\beta$ which would be expected to provide further evidence of how soil erodibility is affected by soil characteristics and soil management (eg. Fig. 11.9). The advantage of using the erodibility parameter $\beta$ described in the GUEST methodology is that it has an approximate physical basis in fundamental soil erosion theory. In comparison, the soil erodibility $K$ in the USLE equation is simply a proportionality factor introduced to ensure agreement between measured soil loss and the adopted product-type arrangement of other factors which do not include runoff or runoff rate.

Field applications of the GUEST program, such as those recorded in this chapter for the ACIAR and ASIALAND projects, benefited from a more fundamental controlled erosion program using simulated rainfall equipment (eg. Proffitt et al. 1993b; Misra and Rose 1995, 1996). These controlled studies supported the theory used in program GUEST, and 
its recognition of the pertinence of soil structural stability and soil strength as two factors affecting soil erodibility. In GUEST, the effect of the size distribution of aggregates and particles on sediment concentration is separated out through recognition in the theory of the role of the soil's settling velocity characteristics (or depositability). Though the erodibility factor $\beta$ evaluated in the Type B version of GUEST is designed to represent properly the effect of soil strength in reducing sediment concentration, its magnitude also incorporates the role of any other factors or processes which contribute to net erosion of soil. Because soil erodibility can be significantly affected by soil management (Rose 1995), and even wetting and drying (Misra and Teixera 2001), the ability to predict the magnitude of $\beta$ is currently limited to general soil characteristics of the type illustrated in Fig. 11.9. However the ACIAR project results (in particular) provide advice on the role of soil management in affecting $\beta$, and support the move towards minimising tillage in agricultural land management (Goddard et al. 2007).

The main purpose and requested aim of this chapter is to describe the GUEST program which (in its simpler Type-B form) enables efficient derivation of the physically-based erosion parameter $\beta$ from experimental data on soil and water loss from an essentially plane bare soil plot in any single erosion event. Of course data from repeated events can add information on time-related change in erodibility, but application of GUEST is not limited to longer-term data sets, as is recommended for the USLE methodology (Edwards 1987). In comparison to WEPP, GUEST is also not limited to information only available in certain regions.

Information on the erodibility of soil in a bare condition is important in soil loss prediction and decision making on the suitability of land for uses which expose it, and in 
the choice from a range of possible soil conserving management systems. However, given the many factors involved in the design and adoption of land-using systems, it is recognised that information on soil erodibility is but one basic desirable input.

Where direct experience is lacking, soil characteristics, soil type, expected soil management and cropping regimes, landscape factors, and the climatic/hydrologic context can all be combined to provide broad guidelines on the danger of soil erosion, and thus the emphasis required in implementing soil conserving management strategies. Of the wide range of such strategies, the agronomically-based experimentation reviewed in this chapter support the effectiveness of soil contact cover (Fig. 11.6) which can be implemented by all types of mulching strategies. The use of vegetative barriers has also been found to be most effective in reducing soil loss, and their implementation in steeper tropical lands, for example, can be encouraged by recognition of their potential role in adding to soil nutrition and productivity. More recent research, based on the same theory as employed in GUEST, has provided a physically-based understanding of the effectiveness of vegetative barriers in reducing soil loss (Rose et al. 2002; Ghadiri et al. 2002; Hussein et al. 2007a,b).

Ongoing work is designed to build on the GUEST approach in ways which address the spatial complexity of natural landscapes (eg. Fentie et al. 2004b). 